взглядов и убеждений, с использованием эмоционально окрашенной деятельности обучающихся.

$* * *$

1. Вилюнас В.К. Психология эмоций. - Спб.: Изд-во Питер, 2006. - 496 с.

2. Гладких В.В. Гражданско-патриотическое воспитание молодежи в поликультурной среде вуза: системно - деятельностный подход: автореф. дисс. доктора. пед. наук: 13.00.05 / В. В. Гладких. Тамбов, 2011.- 50 с.

3. Ильин Е.П. Эмоции и чувства.- Спб.: Изд-во Питер, 2001. - 752 с.

4. Кольцова В.А. Социально-психологические проблемы патриотизма и особенности его воспитания в современном российском обществе / В.А. Кольцова, В.А. Соснин // Психологический журнал. 2011. - Т. 26. - № 4. - С. 89-97.

5. Лернер И.Я. Развивающее обучение с дидактических позиций. М. //Педагогика.-1996.-№2 С. 7 11.

\title{
Капитонова Л.В. \\ Обзор современных российских исследований, посвященных рефлексии и рефлексивности
}

Приамурский государственный университет имени Шолом-Алейхема (Россия, Биробиджан) doi: $10.18411 / l j-02-2021-186$

idsp: ljournal-02-2021-186

\section{Аннотация}

В настоящем обзоре литературы систематизировано 45 научных работ, посвященных рефлексии и рефлексивности, опубликованных с 2006 г. и по настоящее время. Дано определение терминов, показано, что большая часть современных публикаций затрагивает сферу рефлексии и рефлексивности, связанную с проблемами обучающихся и личностными аспектами названных феноменов.

Ключевые слова: рефлексивность, рефлексия, психология, сознание, психическое состояние, личность.

\section{Abstract}

This literature review systematizes 45 scientific papers on reflection and reflexivity, published from 2006 to the present. The definition of the terms is given, it is shown that most of the modern publications concern the sphere of reflection and reflexivity, associated with the problems of students and the personal aspects of these phenomena.

Keywords: reflexivity, reflection, psychology, consciousness, mental state, personality.

Термин «рефлексивность», берет начала от слова «рефлексия», что означает обращение назад, смотрение в себя или на себя. В современном написании термин был помещен в философский словарь немецким мыслителем Платоном Рудольфом Гоклениусом в 1613 г. (Савчук, 2012). В философском аспекте рефлексия способность к отражению, в психологическом - к критическому самоанализу. Элементарная рефлексия, а их выделяют несколько видов, присуща всем людям. Практически все, хоть иногда, задумывались над причинами различных моментов своей жизни и деятельности, над тем, почему и как мы делаем что-либо. Механизм саморефлексии может распространяться и на внешний мир: различают рефлексию по поводу различных сторон и проявлений жизни, природы и человечества в целом; и как ее высшую форму - философскую рефлексию (Энциклопедический словарь, 2004). В другом аспекте рефлексия, это свойство нашего мышления, и в более широком смысле, сознания. С этой стороны, рефлексия есть познание, изучение, обмысливание чего- 
либо. Соответственно, рефлексивность - аналогичное качество, характеристика, способность отдельного человека или группы людей.

Проблему рефлексии рассматривали выдающиеся мыслители человечества начиная с античных времен - Сократ, Платон, Аристотель, Плотин, Д. Локк, Р. Декарт, Г. Лейбниц, И. Кант, И. Фихте, Г. Гегель, М. Хайдеггер, Э. Гуссерель и многие другие (Философская энциклопедия, 1960-1970; Голубева, 2014).

В российской психологии основы изучения рефлексии заложили Б.Г. Ананьев, Л.С. Выготский, С.Л. Рубинштейн, А.Н. Леонтьев (Шигабетдинова, 2014). В дальнейшем вопросы рефлексии успешно изучали Абульханова-Славская К.С., Андреева Г.М., Асмолов А.Г., Брушлинский А.В., Василюк Ф.Е., Емельянов Е.Н., Знаков В.В., Карпов А.В., Леонтьев Д.А, Семенов И.Н., Слободчиков В.И., Степанов С.Ю., Россохин А.В., Щедровицкий Г.П. (Голубева, 2014). Системное же изучение рефлексии в контексте психологии началось в 60-е годы XX в. школой В.А. Лефевра (Новиков, Чхартишвили, 2003).

Г.П. Щедровицкий (2005) показал ширину и многослойность понимания термина «рефлексия», которое зависит от множества факторов: культурных и религиозных традиций, образования, личного жизненного и профессионального опыта отдельных людей и их сообществ. Таким образом, рефлексия и рефлексивность, фундаментальные явления, пронизывающее самые разные сферы жизни и деятельности людей. Изучение рефлексии и рефлексивности на современном этапе развития психологии выливается в становление нового направления - психологии рефлексии (Голубева, 2014).

А.В. Карпов (2003), один из известных современных исследователей рефлексивности, показал, что проблематика этой сферы многогранна, комплексна, связана с разными отраслями и направлениями психологии. На основании анализа литературы, он выделил ее главные направления: деятельностное; в контексте психологии мышления; закономерностей организации коммуникативных процессов; рефлексивность в структуре совместной деятельности; педагогическое; личностное; генетическое; «системомыследеятельностный» подход; метакогнитивная парадигма изучения рефлексивных процессов; как фундаментального механизма самопознания; направление в управленческой деятельности и управлении в целом. Он же показал, что исследования в этих направлениях расширяют, и даже меняют представления об отдельных психологических закономерностях, принятых до настоящего времени в психологической науке, заходя этими изменениями в область общенаучную и мировоззренческую. Кроме того, он сформулировал основные трудности и методологические требования, возникающие в ходе современного изучения рефлексивности, настаивая на особом статусе этого феномена, показывая подходы, разработки и методику ее диагностики.

Отдельной строкой хотелось бы упомянуть важную веху в изучении рефлексии, появление понятий «рефлексивной системы» и «рефлексивного управления», разработанные В.А. Лефевром (1973). В дальнейшем, разработку понятия «рефлексивные игры», что является подходом к современным математическому моделированию рефлексии. Положено начало рассмотрению нового класса теоретикоигровых моделей (рефлексивных игр), которые описывают взаимодействие субъектов или агентов, принимающих решения основываясь на иерархии представлений о существенных параметрах, представлений о представлениях (Новиков, Чхартишвили, 2003), что, собственно, соединяет сферу психологии с математикой, математическим моделированием, управлением социально-экономическими системами.

На современном этапе психологию рефлексии выделяют как инновационное направление. В работах И.Н. Семенова (2008; 2009) детально рассмотрена и проанализирована логика ее развития, этапы изучения в европейской философии и психологии, от античности до современности. Описаны основные научные школы и 
направления изучения рефлексии и рефлексивности в России, взаимосвязь со смежными науками о человеке. Впервые проанализированы истоки отечественной психологии творчества в русской культуре, дифференцированы этапы ее развития в XIX (XXI вв.). Отражен процесс междисциплинарного взаимодействия с другими науками о человеке и обществе.

И если работы в области рефлексии и рефлексивности ведущих исследователей более-менее систематизированы (Карпов, 2003; Щедровицкий, 2005; Семенов, 2008; Голубева, 2014; Сизикова и соавторы 2016), то более частные публикации остаются разрозненными. Соответственно, цель нашей работы, получение представления об изученности феномена рефлексивности на современном этапе развития российской психологии, внесение своего вклада в систематизацию разрозненных исследований и статей, не вошедших в известные нам научные литературные обзоры. Для достижения цели поставлена задача - изучить и систематизировать возможно большее количество современных российских работ, посвященных рефлексии и рефлексивности, в контексте различных проблематик и направлений психологии.

Рефлексия и рефлексивность у обучающихся

Е.А. Митицина (2009) подтвердила связь между уровнем рефлексивности и самореализации. А.В. Черновым (2011) описаны взаимодействия процессов саморегуляции и рефлексии, проходящих в психике в момент трудной ситуации экзамена. А.О. Прохоровым и А.В. Черновым (2012) представлены концептуальные положения рефлексивной регуляции психических состояний. Авторы выявили влияние рефлексии на психическое состояние студентов в разных видах учебной деятельности и eе специфику. В.Д. Щадриков (2012) показал высокую степень взаимосвязи рефлексивности и уровня интеллектуального развития. Им выявлено влияние рефлексии на психические состояния студентов с различным уровнем эмоционального интеллекта. Формирование рефлексивных умений студентов описали И.Б. Афанасьева, А.И. Бежанова, Л.И. Димент (2013). Ими представлена теоретическая база данной тематики и собственные исследования, подтверждающие формирование и увеличение рефлексивных умений студентов в ходе процесса обучения. А.В. Черновым (2013) показано, что рефлексия выражена через эмоциональную гибкость, эмоциональный контроль, эмпатию, понимание эмоций, как своих, так и чужих. В статье В.В. Мацута и С.А. Богомаз (2014) представлен литературный обзор теоретических представлений о рефлексии и социальном интеллекте у первокурсников. А.О. Прохорова и А.В. Чернова (2014) рассмотрели взаимосвязь рефлексии и психических состояний у студентов. Работа Т.А. Соловьевой (2015) посвящена техникам и методическим приемам развития рефлексивности у школьников. В статье М.Е. Валиуллиной (2016) исследована взаимосвязь агрессивности и рефлексивности с некоторыми аспектами образа мира у студентов - будущих педагогов. Рефлексивные процессы в игровых видах спорта и единоборствах обсуждали Г.Д. Бабушкин и Е.Г. Бабушкин (2016). Ими выявлено, что сущность правильного распознавания тактики противника, своих действий и партнеров по игре имеет индивидуальные проявления. Степень этих проявлений зависит от опыта и квалификации спортсмена, а квалификация и уровень рефлексивности - прямо пропорциональны. Р.Р. Денисова (2018) рассмотрела вопросы формирования рефлексии у дошкольников. Работа Е.Е. Чуриловой (2019) посвящена изучению рефлексивного сознания современных юношей и девушек. Выявлены особенности рефлексии и уровня рефлексивности, а также специфика содержательного наполнения самосознания личности в юности. А.В. Чернов (2019) изучал взаимосвязь подструктур психических состояний с типами мотиваций у студентов-психологов. Им отмечено взаимовлияние мотивации социальной полезности и рефлексии на психические состояния студентов-первокурсников. Студенты, с высоким уровнем рефлексивности, мотивированные на социальную полезность, испытывают снижение показателей выраженности психических состояний в процессе учебы. 
Рефлексия и рефлексивность в обучении, у специиалистов обучающих $u$ помогающих профессий

В статье Л.Н. Молчановой (2012) дано обоснование регуляции ценностносмыслового выгорания у врачей, в контексте теорий смысла, рефлексивной регуляции деятельности и других теорий. Рефлексивную позицию тренера изучал А.В. Вощинин (2013) - получена типология рефлексивных позиций, выявлены факторы, определяющие их особенности. Показаны личностные особенности тренеров определенных типов рефлексирования. А.И. Алексеева (2014) составила обзор научной литературы по проблеме применения рефлексивных методик на учебных занятиях в высшем учебном заведении. Особое внимание уделялось материалам, где рассматривалось содержание и этапы применения рефлексивных техник. Д.А. Старовойтова (2014) актуальность проблемы повышения качества педагогических исследований обосновывает через формирование методологической культуры педагога, где методологическая рефлексия системообразующего компонент. В работе В.В. Робского (2015) показано формирование рефлексивной позиции, роли педагога, как другого - понимающего. Рефлексия, как основная составляющая профессии психолога, раскрыта Л.А. Юшковой (2017). Она рассмотрела подходы к изучению рефлексии, проанализировала пять ее параметров: объективность, полнота, системность, глубина, значимость. В работе Т.В. Масовой и А.Н. Фоминовой (2017) отражены личностные корреляты рефлексивности в профессиональном становлении учителя. Это нервнопсихическая устойчивость, индивидуальные стили принятия решений, спонтанность, эмоциональный интеллект. Е.Я. Матюшкиной и А.А. Кантемировой (2019) выявлено, что при выраженной системной рефлексии у специалистов помогающих профессий отсутствуют симптомы профессионального выгорания. При высоких показателях выгорания обнаружен низкий уровень системной рефлексии.

Личностные аспекты рефлексии и рефлексивности

А.В. Ляшук (2006) определил рефлексивность как основную детерминирующую характеристику информационно-психологической безопасности. Ее развитие будет способствовать выстраиванию «стратегии самообеспечения безопасности» и устранению психологических барьеров и блоков, помогать человеку в процессе «введения самого себя в реальность бытия». К.Т. Яновичем (2007) изучались детерминированные отношения между рефлексией и Я - концепцией, а именно, между переменными уровня выраженности рефлексивности и уникальности Я - концепции. В работе А.О. Прохорова и Л.Р. Фахрутдиновой (2009) психическое состояние человека показано через рефлексивный и бытийный слои сознания. Изучая состояние зависимости В.Б. Никишина с соавторами (2011) делает вывод об опосредующей роли рефлексивности по отношению к системе «доверия-недоверия». Ими описаны видоспецифические и общие особенности разрушения взаимосвязи в системе «довериенедоверие» и рефлексивности. И.Н. Семенов (2014) представил обзор теоретикоэкспериментальных работ рефлексивной организации творческого мышления, с использованием метода содержательно-смыслового анализа. Работа Е.Б. Старовойтенко (2013) посвящена проблеме развития личности в аспекте рефлексии и реализации ее возможностей в отношении к другому человеку, где за основу взято осознанное знание, переживание и реализация «Я могу». Рефлексивная регуляция показана через переживания человека, где последние являются опосредующим звеном (Габдреева, 2014). Г.М. Шигабетдиновой (2014) изучался механизм рефлексии во взаимодействии социальных субъектов. Показаны взаимосвязи между эмоциональными и волевыми процессами. М.В. Чумаковым (2016) исследовалась эмоционально-волевая регуляция как рефлексивный процесс, имеющий метауровень. В этом процессе выявлена центральная структурная позиция эмоций. В статье А.В. Чернова (2016) показаны 
особенности взаимосвязи личностного смысла и рефлексии с психическими состояниями человека, возникающими в ходе трудовой деятельности. Личностные аспекты (ценности, намерения, предпочтения, самораскрытие, самопознание) показаны через анализ self-рефлексивных форм (Анистратенко, 2017). Рефлексию, как форму субъектности сознания (способность рефлексивного воздействия сознания одного субъекта на сознание другого) изучала М.В. Цветкова (2018).

Рефлексия и рефлексивность в консультативной практике

Работа Т.Э. Сизиковой и Т.В. Волошиной (2012) посвящена новому направлению - рефлексивному психологическому консультированию. Эти же авторы рассмотрели типологию проблем клиентов рефлексивного психологического консультирования и методологический подход к моделированию проблем разных видов психологической помощи (Сизикова, Волошина, 2015; 2016). Т.Э. Сизикова $(2016,2017)$ раскрыла сущность рефлексивного психологического консультирования. В другой работе этого автора описаны три элементарные единицы рефлексии. А именно, «разрыв - ресурс», «разотождествление - отождествление», «систематизация - синтез». Выявлено, что элементарной психологической, побудительной единицей процесса консультирования является структура «рефлексия - мотив - воля» (Сизикова, 2017а). Виды рефлексивного психологического консультирования описаны Т.Э. Сизиковой и Н.А. Стунжей (2017).

Работы, затрагивающие более широкие трактовки различных сфер рефлексии и рефлексивности и другие проблематики

Феномен рефлексии, как предмет научно-психологического изучения, границы этого понятия рассмотрены Г.М. Шигабетдиновой (2014). И.Н. Семенов (2015) на эмпирическом материале произвел рефлексивно-психологический анализ интроспективного саморазвития жизни и творчества писателя М.М. Зощенко. Н.Д. Шатовой (2016) представлена современная онтология рефлексии, на основе материалистической трактовки психики и мышления, с подключением данных нейрофизиологии, где рефлексивная потребность (ощущается как желание осознать собственную мыслительную деятельность) выражена нарушением динамического равновесия организма и возникновением повышенного возбуждения в нейронных системах головного мозга. Т.Г. Анистратенко (2016) систематизировала представления о рефлексивности, как о трансдисциплинарном подходе с позиций современного гуманитарного знания. Автор показала общее мнению исследователей, о приобретении человеком способности принятия решений, управления своими состояниями, свободы выбора, вследствие чего происходит формирование субъекта своей жизни и социальных отношений. В работе С.В. Толстой и О.В. Бондаренко (2017) рассмотрены функция и место понятия «рефлексия» в психологической науке. Акцентировано внимание на рефлексии в социально-психологическом контексте, саморегуляции, деятельности человека, роли в личностном компоненте мышления.

Таким образом, из 45 систематизированных работ большая часть посвящена рефлексии и рефлексивности у обучающихся (14) и затрагивающая личностные аспекты этих феноменов (12). В меньшем количество представлены работы, касающиеся проблематик обучения, обучающих-помогающих профессий и консультативной практики (8 и 7 соответственно).

Особое внимание нами уделено блоку работ по рефлексии и рефлексивности у обучающихся. Данные исследования в основном показывают этап установления связи феноменов рефлексии или рефлексивности с различными аспектами жизни людей, которые чему-либо учатся. В данном блоке, таких работ 11 из 14. Это факт может указывать на наборе фактической массы психологией рефлексии в данном 
направлении. Соответственно, вклад в познание вопросов взаимосвязи аспектов жизни людей и рефлексивности видится очень актуальным.

$$
\text { *** }
$$

1. Алексеева А.И. Методика организации рефлексивного этапа на учебных занятиях в вузе // Научный диалог. Психология. Педагогика. № 11 (35). 2014. С. 6-15.

2. Анистратенко Т.Г. Интегративный характер социальной рефлексии: монография. Южный федеральный университет. Ростов-на-Дону. Таганрог: Издательство Южного федерального университета. 2017. $348 \mathrm{c.}$

3. Анистренко Т.Г. Социальная рефлексия: трансдисциплинарный подход // Гуманитарные, социально-экономические и общественные науки. №8-9. 2016. С. 25-29. (Электронный ресурс).

4. Афанасьева И.Б., Бежанова А.И., Димент Л.И. Формирование рефлексивных умений студентов в процессе обучения // Научно-технические ведомости СПбГПУ. № 1 (166). 2013. С. 292-299.

5. Бабушкин Г.Д., Бабушкин Е.Г. Рефлексия и рефлексивность в структуре спортивной деятельности // Научное обозрение. Реферативный журнал. № 6. 2016. С. 80-82.

6. Валиуллина М.Е. Образ мира, агрессивность и рефлексивность у студентов педагогического профиля // Ученые записки Казанского университета. Серия Гуманитарные науки. Т. 158. №4. 2016. C. 941-949.

7. Вощинин А.В. Рефлексия в структуре деятельности тренера: от рефлексивной позиции к рефлексивной культуре // Теория и практика физической культуры. №2. 2013. С. 12-18.

8. Габдреева Г.Ш. Роль переживаний в рефлексивной регуляции состояний // Ученые записки Казанского университета. Серия Гуманитарные науки. Том 156. №6. 2014. С. 164-177.

9. Денисова Р.Р. Рефлексия в дошкольном возрасте: вопросы теории // Ученые записки ЗабГУ. Т. 13. №3. 2018. C 101-106.

10. Ляшук А.В. Рефлексивность в обеспечении информационно-психологической безопасности личности // Известия ТРТУ. Тематический выпуск «Психология и педагогика». № 14 (69). 2006. С. 371-377.

11. Матюшкина Е.Я., Кантемирова А.А. Профессиональное выгорание и рефлексия специалистов помогающих профессий // Консультативная психология и психотерапия. Т. 27. № 2. 2019. С. 5068.

12. Маясова Т.В., Фоминова А.Н. Сравнительный анализ личностных коррелятов рефлексивности в контексте профессионального становления учителя // «Вестник Мининского университета». № 2. 2017. (Электронный ресурс).

13. Мацута В.В., Богомаз С.А. Связь рефлексии и социального интеллекта у студентов первого курса // Сибирский психологический журнал. №51. 2014. С. 53-64.

14. Митицина Е.А. Рефлексивные особенности студентов с различными уровнями самореализации // Вестник Псковского государственного университета. Серия: Социально-гуманитарные науки. №11. 2009. C. 62-65.

15. Молчанова Л.Н. Рефлексия как механизм ценностно-смысловой регуляции состояния психического выгорания у врачей // Известия Саратовского университета. Новая серия. Философия. Психология. Педагогика. №1. 2012. С. 64-68.

16. Никишина В.Б., Запесоцкая И.В., Копылова П.В. Рефлексивный компонент интегративной модели доверия-недоверия при состоянии зависимости // Аддиктивное поведение: профилактика и реабилитация. Материалы конференции 22-23 апреля 2011 г. Московский государственный психолого-педагогический университет. 2011. С. 192-200.

17. Прохоров А.О. Фахрутдинова Л.Р. Рефлексийный и бытийный слои психического состояния // Ученые записки Казанского государственного университета. Серия Гуманитарные науки. Т. 151-5, Ч. 1. 2009. С. 1-13.

18. Прохоров А.О., Чернов А.В. Рефлексивная регуляция психических состояний // Ученые записки Казанского университета. Гуманитарные науки. Т. 154. Кн. 6. 2012. С. 244-257.

19. Прохоров А.О., Чернов А.В. Влияние рефлексии на интенсивность психических состояний студентов в процессе учебной деятельности // Экспериментальная психология. Т. 7. №2. 2014. С. 82-93.

20. Робский В.В. Трудности педагогической рефлексии // ИСОМ. Приложение 2. 2015.

21. Сизикова Т.Э. Рефлексивное психологическое консультирование. Часть 1. Психологическая сущность рефлексии. Новосибирск: НГПУ. 2016. 203 с.

22. Сизикова Т.Э. Рефлексивное психологическое консультирование. Часть 2. Теория рефлексивного психологического консультирования. Новосибирск: НГПУ. 2017. 407 с. 
23. Сизикова Т.Э. Элементарные единицы рефлексивного психологического консультирования // Вестник КГУ. Педагогика. Психология. Социокинетика. № 2. 2017а. С. 81-86.

24. Сизикова Т.Э., Волошина Т.В. Рефлексивное психологическое консультирование как новое направление оказания психологической помощи // Сибирский педагогический журнал. № 3. 2012. С. $183-188$.

25. Сизикова Т.Э., Волошина Т.В. Типология проблем для рефлексивного психологического консультирования // Сибирский педагогический журнал. № 1. 2015. С. 74-79.

26. Сизикова Т.Э., Волошина Т.В. Методологический подход к моделированию системы психологических проблем для разных видов психологической помощи // Сибирский педагогический журнал. № 3. 2016. С. 107-113.

27. Сизикова Т.Э., Стунжа Н.А. Виды рефлексивного психологического консультирования // Актуальные проблемы развития личности в современном мире. №1. 2017. С. 69-80.

28. Семенов И.Н. Опыт изучения рефлексивности творческого мышления методом содержательносмыслового анализа // Психология. Историко-критические обзоры и современные исследования. №5. 2014. C. 10-57.

29. Семенов И.Н. Рефлексивность самонаблюдения и персонология интроспекции: к онтологии и методологии рефлексивной психологии индивидуальности (окончание) // Вестник Московского университета. Серия 14. Психология. №4. 2015. С. 98-113.

30. Старовойтенко Е.Б. Возможности я в отношении к другому: герменевтика и рефлексия // Психология. Журнал Высшей школы экономики. 2013. Т. 10. № 4. С. 121-142.

31. Старовойтова Д.А. Сущность и содержание методологической рефлексии педагога // Ярославский педагогический вестник. № 1. Том II (Психолого-педагогические науки). 2014. С. 33-37.

32. Соловьева Т.А. Рефлексия в образовательном процессе школы // Современные проблемы образования в поликультурном регионе (Шестые Лозинские чтения): Материалы Международной научно-методической конференции 23-24 апреля 2015 г. Часть I. Псков: Псковский государственный университет. 2015. С. 15-20.

33. Толстая С.В., Бондаренко О.В. Анализ понятия рефлексия в психологической литературе // Проблемы современной науки и образования. № 33 (115). 2017. С. 60-65.

34. Цветкова М.В. Рефлексия как форма проявления субъектности сознания // Психология и Психотехника. №2. 2018. С. 22-29.

35. Чернов А.В. Влияние рефлексии и регуляторных процессов на интенсивность психических состояний студентов в ситуации экзамена // Ученые записки Казанского университета. Серия Гуманитарные науки. Т. 153., №5. 2011. С. 127-136.

36. Чернов А.В. Влияние рефлексии на психические состояния студентов с различным уровнем эмоционального интеллекта: дис. ... уч. степ. канд. псих. наук / А.В. Чернов. - Казань. 2013. 184 с.

37. Чернов А.В. Роль личностного смысла и рефлексии в регуляции психических состояний // Психология состояний: сборник материалов юбилейной Международной школы. Под ред. Б.С. Алишева, А.О. Прохорова. Казань: Изд-во Казан. ун-та. 2016. С. 234-241.

38. Чернов А.В. Роль мотивации и рефлексии в регуляции психических состояний студентов // Методология, теория, история психологии личности / Отв. ред. А. Л. Журавлев, Е.А. Никитина, Н.Е. Харламенкова. М.: Изд-во «Институт психологии РАН». 2019. С. 715-722.

39. Чумаков М.В. Эмоционально-волевая регуляция как рефлексивный процесс // Вестник ЯрГУ. Серия Гуманитарные науки. № 1 (35). 2016. С. 88-92.

40. Чурилова Е.Е. Рефлексивное сознание личности в юности // Современные проблемы науки и образования. Международная научно-практическая конференция современные проблемы науки и образования, Чебоксары, 26 июля 2019 г. Изд-во «Экспертно-методический центр». 2019. С. 348352.

41. Шадриков В.Д. Роль рефлексии и рефлексивности в развитии способностей учащихся // Психология. Журнал Высшей школы экономики. Т. 9, № 4. 2012. С. 133-144.

42. Шатова Н.Д. Современная материалистическая онтология рефлексии // Вестник Пермского университета. Выпуск 2/26. 2016. С. 24-31.

43. Шигабетдинова Г.М. Феномен рефлексии: границы понятия // Вестник Нижегородского университета им. Н.И. Лобачевского. Социология. Психология. Философия. № 2 (1). 2014. С. $415-$ 422.

44. Юшкова Л.А. Рефлексивность как составляющая профессии психолога // Развитие человека в современном мире. №2. 2017. С. 144-150.

45. Янович К.Т. Я концепции в соотношении к уровням развития рефлексии // Рефлексивные процессы и управление. № 2, т. 7. 2007. С. 57-68. 